\title{
Are older and seriously ill inpatients planning ahead for future medical care?
}

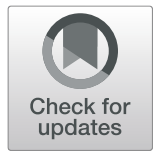

Amy Waller ${ }^{1,2^{*}} \mathbb{D}$, Rob Sanson-Fisher ${ }^{1,2}$, Balakrishnan R (Kichu) Nair ${ }^{3,4}$ and Tiffany Evans ${ }^{5}$

\begin{abstract}
Background: Despite the perceived ethical, personal and health service benefits of advance care planning (ACP), the extent to which older and seriously ill Australian inpatients have considered future health decisions remains uncertain. This study aimed to determine in a sample of older and seriously ill inpatients, the proportion who had: 1) engaged in four advance care planning (ACP) activities; 2) not engaged in ACP activities but wanted to; and 3) reasons why they had not engaged.

Methods: Cross-sectional face-to-face standardised interview survey with inpatients in a tertiary referral centre who were either: aged 80+ years; aged 55+ years with progressive chronic disease(s); or judged by treating clinicians as having a life expectancy of less than 12 months. Patients indicated whether they had engaged in four ACP activities: (1) appointed medical substitute-decision-maker(s), (2) recorded end-of-life wishes in an advance directive or care plan; and talked about their end-of-life wishes with their: (3) support persons and/or (4) doctors. Patients who had not engaged in activities were asked whether they wished this to occur and reasons why.

Results: One hundred eighty-six inpatients consented to the study (80\% of approached). Of these, $9 \%(n=16)$ had engaged in four ACP activities; $27 \%(n=50)$ had not engaged in any. Half $(n=94,52 \%)$ had appointed a medical substitute-decision-maker, 27\% $(n=50)$ had recorded wishes in an advance directive or care plan, 51\% $(n=90)$ had talked about their end-of-life wishes with support persons and 27\% $(n=48)$ had talked with their doctor. Patients who wanted to, but had not, engaged in the four ACP activities were unaware they could record wishes or appoint decision -makers, or indicated providers had not initiated conversations.
\end{abstract}

Conclusion: Relatively few inpatients had engaged in all four ACP activities. More inpatients had discussed end of life issues with family and appointed substitute decision makers, than completed written documents or talked with doctors. Community education and a more active role for community and hospital-based providers in supporting patients and families to collaboratively resolve end-of-life decisions may increase the probability wishes are known and followed.

Keywords: End-of-life, Advance care planning, Acute care

\section{Background}

Advance care planning (ACP) is an "ongoing process that supports adults at any age or stage of health in understanding and sharing their personal values, life goals, and preferences regarding future medical care" [1]. ACP is relevant for people considering the likely medical outcomes for treatment decisions at the end of life; and

\footnotetext{
* Correspondence: amy.waller@newcastle.edu.au

${ }^{1}$ Health Behaviour Research Collaborative, School of Medicine and Public Health, Faculty of Health and Medicine, University of Newcastle, Callaghan, NSW 2308, Australia

${ }^{2}$ Hunter Medical Research Institute, New Lambton Heights, NSW 2305,

Australia

Full list of author information is available at the end of the article
}

clarifying a person's values and what their goals for future care might be [2]. ACP includes a range of key activities including conversations about values, preferences and important priorities with support persons and/or healthcare providers. ACP conversations often lead to the completion of an advance care directive, which is a written document recognised by common law or statutory legislation and/or legal appointment of someone to make decisions on their behalf (i.e. a substitute decisionmaker) [3]. ACP has improved compliance with individuals' goals of care and end-of-life wishes, reduced depressive symptoms and family stress $[4,5]$, and lowered costs and hospital presentations [6].

(c) The Author(s). 2019 Open Access This article is distributed under the terms of the Creative Commons Attribution 4.0 International License (http://creativecommons.org/licenses/by/4.0/), which permits unrestricted use, distribution, and 
A systematic review reported that many frail and older people who would like to engage in advance care planning are not offered this opportunity [7]. Such discussions are often delayed until a person is imminently dying [8], even though an estimated $40 \%$ of people will lack capacity to participate in decisions in these circumstances. Much of the available data on $\mathrm{ACP}$ has been obtained in the United States of America (USA) over the past three and a half decades, with the reported prevalence of advance care directive ownership ranging from $26 \%$ to as high as $70 \%$ among those aged 65 years or over [9]. An international comparison study found that completion of written plans describing treatment options varied among 15,617 older adults in Germany (58\%), Australia (31\%), the United Kingdom (20\%), Canada (46\%) and Norway (4\%) [10]. Overseas findings may not generalise to the Australian environment given differences in health care delivery and political and societal norms [2].

In comparison, there is limited patient-reported data on the level of engagement in different ACP activities in Australia [11], particularly amongst those who are older (defined here as 55 years of age or over) and those who have been diagnosed with life limiting illnesses other than cancer [11]. In the first national population-based study, only $14 \%$ of 2045 adults in the general community had prepared an advance care directive [12]. People were much more likely to have completed wills and appointed financial powers of attorney in comparison [12]. One third of 1600 older Australians in the community reported having prepared a written document outlining their end-of-life wishes in another study [10]. More recently, a prevalence audit study reported an overall rate of advance care directive ownership among 2285 people aged 65 years or over of $30 \%$. Rates ranged from $48 \%$ among residents of aged care facilities to $16 \%$ of hospital patients and 3\% of general practice patients [13].

Previous studies of ACP engagement often rely on retrospective audits or provider views [11, 13-15]. An advantage of obtaining patient views over these methods is that uptake and utility can be explored in the context of patients' preference to engage in ACP [11]. Eliciting preferences at a particular time point can provide greater clarity about whether rates of uptake represent a gap in care or are a result of patient preference. Furthermore, very few studies have explored Australian inpatients reasons for not having engaged in ACP [16, 17]. Consequently, this study examined in a sample of older and seriously ill inpatients, the proportion who had: 1) engaged in each of four key advance care planning activities; 2) not engaged in the advance care planning activities but wanted to; and 3) their reasons why they had not engaged.

\section{Methods \\ Design}

A cross-sectional interview study of older and seriously ill inpatients recruited from general medicine, renal and geriatric wards in a single tertiary teaching hospital in Australia.

\section{Sample}

Potentially eligible inpatients were admitted to participating wards and judged by staff as being cognitively and physically able to give informed consent and complete the interview. Criteria were adapted from a previous Canadian study [18]. Eligible patients were either: (a) aged 80 years and over; (b) aged 55 years or over and diagnosed with one of the following conditions: (i) congestive heart failure; (ii) chronic obstructive lung disease; (iii) cirrhosis; (iv) metastatic cancer; and/or (v) chronic renal failure; or (c) aged 55 years or over and judged by physicians to have a life expectancy of less than 12 months. Only those admitted for $\geq 48 \mathrm{~h}$ were approached, allowing time for necessary emergency care to be delivered [18].

\section{Procedure}

The charge nurse in the selected wards identified eligible inpatients from ward lists. If the inpatient indicated they were willing to talk to a trained research assistant (RA), the RA then provided verbal and written information that the study was exploring peoples' views about endof-life care and decision-making, answered any questions the inpatient had and obtained written informed consent. Standardised interviews were conducted with consenting inpatients at their bedside. Individuals were able to complete the interview at a time that their family member was present if they preferred, however patients answered the survey items themselves. The age and sex of all eligible non-consenting inpatients was recorded.

\section{Development of survey}

Establishing the validity and reliability of measures of end of life and advance care planning remains a difficult area. Published literature in the field highlights this problem and the pragmatic, ethical, and psychometric difficulties have been acknowledged [3, 19-21]. At the time of data collection, no psychometrically robust selfreport measures were available that included the broad range of end of life topics covered in this study. Therefore, a study-specific survey has developed using the following process. First, healthcare providers and consumers participated in 20-min individual interviews to elicit their views and experiences. Potential items were 
then reviewed by a panel including a geriatrician, oncologist, surgeon, nurse, nephrologist, palliative care physician and behavioural scientists until consensus on content and format of items was reached. Items were then modified and pilot tested with a convenience sample of 20 inpatients for acceptability, relevance and clarity, and refined based on their feedback.

\section{Measures}

The items described here (see Additional File 1) are drawn from a larger set of survey items, some of which will be reported elsewhere because they address different themes. The following definitions of 'ACP' were provided. "ACP provides an opportunity for people to think, discuss and plan for the medical treatment they would prefer if they became too ill in the future to express their wishes. Everyone should consider advance care planning, regardless of their age or health. But it is particularly important for people who have ongoing health problems. These questions ask for your views and experiences in talking and making decisions about your future medical care, including end of life care".

\section{Self-reported engagement in ACP activities}

Patients were asked whether they had engaged in each of the four ACP activities including: (1) "written down your wishes for end-of-life health care (e.g. in an advance directive or care plan"); (2) "appointed a medical substitute-decision-maker (i.e. legally appointed to make medical decisions on your behalf if you can't yourself)". (3) "talked about the type of end-of-life health care you would like to receive with your support person"; and (4) "talked about the type of end-of-life health care you would like to receive with your doctor". Standard definitions were provided. Response options for each item were 'yes', 'no but I would like to', 'no but I do not want to' or 'unsure'. Further explanation was offered if these terms were not clear.

\section{Reasons for non-engagement}

For each item, open-ended responses were then sought by the interviewer. Those who responded to the questions with a 'no, but I would like to' were asked "What has stopped you from engaging in the [ACP activity]?". Those who indicated that they did not want to engage in any of the listed ACP activities were asked why they did not want to engage.

\section{Financial planning}

Patients were asked whether they had: (1) "made a will"; and (2) "appointed an enduring financial power of attorney (i.e. someone legally appointed to make financial decisions on your behalf'). Response options for each item were 'yes', 'no but I would like to', 'no but I do not want to' or 'unsure'.

\section{Socio-demographic and clinical variables}

Were obtained via patient self-report, including sex, age, country of birth, religion, living arrangements and perceived quality of life and health (both rated on a single item 0-10 scale; higher scores indicated better quality of life or health). Clinical items included self-reported reason(s) for admission and medical condition(s).

\section{Statistical analysis}

Statistical analyses were programmed using SAS software v9.4 (SAS Institute, Cary, North Carolina, USA). Socio-demographic, clinical characteristics, and responses to ACP questions were summarised as frequencies, and percentages of non-missing responses. Open-ended responses were elicited for patients who indicated they had not engaged in ACP however not all patients chose to give a response. Chi-square or Fisher's exact tests for independence were performed for survey items with sub-group (i.e. 55-79 years vs $80+$ years). The sample size allowed estimation of population proportions within a $7 \%$ margin of error.

\section{Results}

Sample

A total of 186 inpatients consented to participate $(80 \%$ of 233 approached). Of these, $64 \%$ were aged 80 years or over, $57 \%$ were female and $95 \%$ resided in the community either in their own home or the home of a relative or friend prior to admission (see Table 1). There were significant age differences $(\times 2=5.78, P<0.05$; fewer $80+$ year old patients) compared with those who withheld consent to participate.

\section{Engagement in four advance care planning (ACP) activities}

Figure 1 presents the number of ACP activities patients self-reported they had engaged in (i.e. talked about their end-of-life wishes with support person(s), talked about their end-of-life wishes with doctor, recorded wishes in an advance directive or care plan and/or appointed a medical substitute-decision-maker). Overall, $9 \%$ of the respondents had $(n=16)$ engaged in all four ACP activities; $27 \%(n=50)$ had not engaged in any of the identified ACP activities.

Table 2 describes the proportion of patients who had engaged in each of the four ACP activities. Overall, 51\% $(n=90)$ of had talked about their end of life wishes with support persons, 52\% $(n=94)$ had appointed a medical substitute-decision maker, 27\% $(n=48)$ had talked about their end of life wishes with their doctor and $27 \%(\mathrm{n}=50)$ had written down their 
Table 1 Socio-demographic and clinical characteristics of the participant sample

\begin{tabular}{llll}
\hline & $\begin{array}{l}5579 \text { years } \\
(n=65)\end{array}$ & $\begin{array}{l}80 \text { years or over } \\
(n=116)\end{array}$ & $\begin{array}{l}\text { Total } \\
(N=186)\end{array}$ \\
\hline $\begin{array}{l}\text { Sex } \\
\text { Male }\end{array}$ & $28(43 \%)$ & $49(42 \%)$ & $80(43 \%)$ \\
$\quad \begin{array}{l}\text { Female } \\
\text { Australian born } \\
\text { Yes }\end{array}$ & $37(57 \%)$ & $67(58 \%)$ & $106(57 \%)$ \\
No & $56(86 \%)$ & $104(90 \%)$ & $165(89 \%)$ \\
Re & $9(14 \%)$ & $12(10 \%)$ & $21(11 \%)$
\end{tabular}

Religion

$\begin{array}{llll}\text { Catholic } & 20(31 \%) & 20(18 \%) & 40(22 \%) \\ \text { Anglican } & 14(22 \%) & 31(27 \%) & 47(26 \%) \\ \text { Muslim } & 4(6.2 \%) & 10(8.8 \%) & 14(7.6 \%) \\ \text { No religion } & 16(25 \%) & 28(25 \%) & 45(24 \%) \\ \text { Other } & 11(17 \%) & 25(22 \%) & 38(21 \%)\end{array}$

Living arrangements

$\begin{array}{llll}\text { Home alone } & 29(45 \%) & 58(50 \%) & 90(49 \%) \\ \text { Spouse/partner } & 23(35 \%) & 29(25 \%) & 54(29 \%) \\ \text { Relative } & 9(14 \%) & 17(15 \%) & 26(14 \%) \\ \text { Nursing home } & 3(4.6 \%) & 6(5.2 \%) & 9(4.9 \%) \\ \text { Other } & 1(1.5 \%) & 5(4.3 \%) & 6(3.2 \%)\end{array}$

Reason for admission*

$\begin{array}{llll}\text { Fall } & 13(21 \%) & 36(31 \%) & 49(27 \%) \\ \text { Pneumonia } & 2(3.2 \%) & 5(4.4 \%) & 7(3.9 \%) \\ \text { Shortness of breath } & 5(7.9 \%) & 9(8.0 \%) & 14(7.7 \%) \\ \text { Fracture } & 0 & 4(3.5 \%) & 4(2.2 \%) \\ \text { Infection } & 7(11 \%) & 8(7.1 \%) & 15(8.8 \%) \\ \text { Other } & 47(72 \%) & 68(60 \%) & 115(64 \%)\end{array}$

Medical conditions*

\begin{tabular}{llll} 
Cancer & $9(14 \%)$ & $15(14 \%)$ & $25(14 \%)$ \\
COPD & $6(9.4 \%)$ & $10(9.0 \%)$ & $17(9.4 \%)$ \\
Heart failure & $13(20 \%)$ & $21(19 \%)$ & $35(19 \%)$ \\
Renal disease & $25(39 \%)$ & $10(9.0 \%)$ & $35(19 \%)$ \\
Diabetes & $19(30 \%)$ & $11(9.6 \%)$ & $31(17 \%)$ \\
Other & $40(63 \%)$ & $80(72 \%)$ & $123(69 \%)$ \\
\hline
\end{tabular}

*Multiple response items, column does not add to $100 \%$. Column frequencies may not sum to 186 due to missing data

wishes in an advance directive or care plan. Of the 94 respondents who had appointed a medical substitute-decision-maker, the majority had appointed their children $(n=79)$ or spouse/partner $(n=9)$. However, only one third had told their healthcare providers about the appointment $(32 \%, n=29)$. Only $50(27 \%)$ respondents had recorded wishes in an advance directive or care plan. Healthcare provider(s) $(44 \%, n=$ $22)$, family $(36 \%, n=18)$ and/or solicitor(s) $(18 \%, \mathrm{n}=$ 9) were involved in the preparation of these

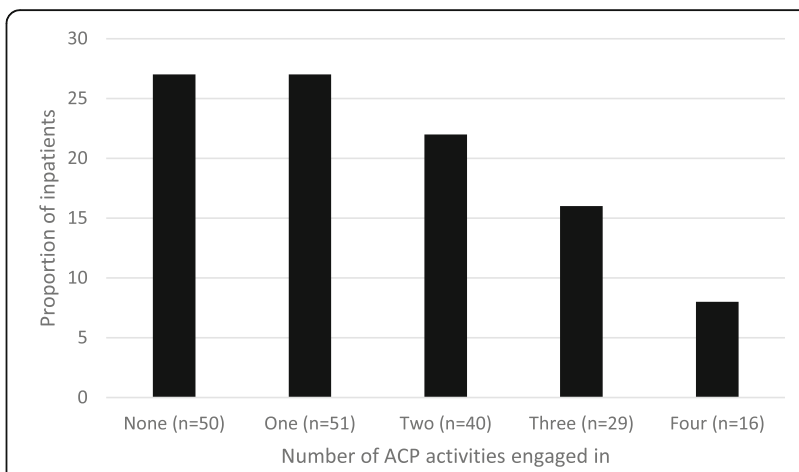

Fig. 1 The total number of advance care planning activities engaged in by participants

documents. End-of-life conversations occurred most often with children $(n=69)$, spouse/partners $(n=20)$ and/or other family/friends $(n=7)$. End of life conversations occurred more often with general practitioners (GPs) $(n=34)$ than with hospital-based clinician(s) $(n=14)$ and/or aged care home staff $(n=3)$.

\section{Desire to engage in each of the four ACP activities}

Of the 133 patients who had not already recorded their end-of-life wishes in an advance directive or care plan, $42 \%(n=56)$ wanted to do so (Table 2). Of the 88 patients who had not already appointed a medical substitute-decision-maker, $53 \%(n=47)$ indicated they wish to take such an action. Further, 33\% ( $n=29 / 87$ inpatients) who had not talked about their end-of-life wishes with their support person wanted to have such a discussion; and $44 \%$ ( $n=57 / 130$ inpatients) who had not talked about their end of life wishes with their doctor wanted to do this. Among participants who had not written down their wishes for end of life care, those who were aged $80+$ years were less likely to want to do so compared to those aged 55-79 years with progressive diseases $(51 \%$ vs $27 \%, p<0.05)$. There were no significant differences between the two age groups for any other ACP activity (see Table 2).

\section{Reasons why patients had not engaged in ACP}

Only $59 \%(n=106)$ of respondents were familiar with the concept of a 'medical substitute-decision-maker' and $24 \%(n=43)$ with an 'advance care directive'. Among those patients who had not engaged in at least one of the four ACP activities but wanted to $(n=98)$, the most common reasons were: they had 'just not thought about it before' $(n=60)$; they had never heard of the activity $(n=31)$; or had not had an opportunity to engage in the activity $(n=6)$. Some inpatients reported they had initiated but had not completed the activity (e.g. made an appointment to prepare a written document) $(n=15)$. Others did not provide reasons. 
Table 2 Prevalence of engagement in advance care planning activities in whole sample and by sub-group

\begin{tabular}{|c|c|c|c|c|}
\hline & Total $(N=186)$ & $55-79$ years $(n=65)$ & $80+$ years $(n=116)$ & $\mathrm{p}$ \\
\hline \multicolumn{4}{|c|}{ Discussed preferred end of life care with doctor } & 0.6396 \\
\hline Yes & $48(27 \%)$ & $14(23 \%)$ & $33(29 \%)$ & \\
\hline Not engaged but wanted to & $57(32 \%)$ & $21(34 \%)$ & $35(31 \%)$ & \\
\hline Not engaged and did not want to & $73(41 \%)$ & $27(44 \%)$ & $45(40 \%)$ & \\
\hline \multicolumn{4}{|c|}{ Discussed preferred end of life care with support person } & 0.6058 \\
\hline Yes & $90(51 \%)$ & $28(45 \%)$ & $59(53 \%)$ & \\
\hline Not engaged but wanted to & $29(16 \%)$ & $12(19 \%)$ & $17(15 \%)$ & \\
\hline Not engaged and did not want to & $58(33 \%)$ & $22(36 \%)$ & $36(32 \%)$ & \\
\hline \multicolumn{4}{|l|}{ Written down wishes for end of life care } & 0.0043 \\
\hline Yes & $50(27 \%)$ & $20(31 \%)$ & $28(24 \%)$ & \\
\hline Not engaged but wanted to & $56(31 \%)$ & $27(42 \%)$ & $28(24 \%)$ & \\
\hline Not engaged and did not want to & 77 (42\%) & $17(27 \%)$ & $59(51 \%)$ & \\
\hline \multicolumn{4}{|c|}{ Appointed a medical substitute-decision maker } & 0.1904 \\
\hline Yes & $94(52 \%)$ & $31(48 \%)$ & $60(53 \%)$ & \\
\hline Not engaged but wanted to & $47(26 \%)$ & $22(34 \%)$ & $25(22 \%)$ & \\
\hline Not engaged and did not want to & $41(23 \%)$ & $12(19 \%)$ & $29(25 \%)$ & \\
\hline
\end{tabular}

significant $p$-value is in bold and italics

For those who had not engaged in at least one of the four ACP activities but did not want to $(n=87)$, the most common reasons were they: felt their family (or doctor) knew what they wanted already $(n=64)$; were 'just not interested' $(n=57)$; perceived they would not get any benefit by participating $(n=34)$; did not have a regular or trusted healthcare provider $(n=9)$; wanted to avoid burdening others $(n=6)$; or did not want others making decisions for them $(n=6)$.

\section{Engagement in financial planning}

The majority of respondents had made a will $(90 \%$, $n=151$ ), and most had an enduring financial power of attorney $(74 \%, n=124)$. Of those who had not already done so, $47 \%(\mathrm{n}=8$ of 17$)$ wanted to prepare a will and $51 \%$ ( $n=19$ of 37 ) wanted to appoint an enduring financial power of attorney.

\section{Discussion}

Despite their estimated limited life expectancy, 27\% of patients had not engaged in any of the four ACP activities and 9\% had engaged in all four activities. It is acknowledged that discussion and documentation may not cover all eventualities that an individual may face regarding their future health care [22]. However, it is likely that the presence and discussion of such issues may assist patients and their substitute decision-makers so that care consistent with patient's wishes is more likely to be provided [22].

Half of respondents had formally appointed a medical substitute-decision-maker. Without a clear designation of authority it is possible that conflicts may emerge in families and healthcare teams when there is an attempt to determine what end-of-life care an individual might prefer [23]. While the order of priority in which people are approached if someone has not been formally nominated is determined by statutes in Australia, studies show that a person's preference does not always reflect this hierarchy. For instance, 30\% of ICU patients preferred another trusted advocate rather than spouse to be their decision-maker [24]. Similar rates of documentation of end of life wishes were reported for the two groups (24 and $31 \%)$. Older age has been previously associated with greater ACP engagement [25-27]; while others have not reported any association between age and engagement [28]. Our findings suggest that younger patients with progressive diseases are an important target for initiating formal advance care planning processes, as a higher proportion indicated they had not, but wanted to write down their wishes.

While half of the respondents had discussed their endof-life wishes with a support person, only a quarter had done so with a healthcare provider. Early conversations can increase the likelihood that patients have sufficient capacity to meaningfully engage, reduce time pressures that can prevent the patient from adequately reflecting on and discussing wishes, and enhance opportunities for multi-disciplinary input $[29,30]$. Involving substitute-decision makers early may also avoid placing these individuals in an emotionally vulnerable and fraught decision situation. Of those who had talked to a healthcare provider, most reported conversations with their GP rather 
than a hospital-based clinician. This is not surprising, as GPs are a frequent point of contact and have a key longitudinal role in caring for older people [31]. However, not all GPs are skilled and comfortable discussing likely future scenarios for the end of life [32]. Further, GPs are unlikely to be involved in end-of-life decisions and actions for the significant proportion of older people who will die in hospital. A mechanism by which patient wishes can be effectively and accurately communicated between GPs and hospital providers is therefore important.

This is one of the first Australian studies to provide patient-reported data to quantify the gap between what older and seriously ill inpatients want and what is currently occurring in relation to ACP. Awareness of and opportunities to engage in ACP activities in the inpatient setting appear limited. To achieve improvements in ACP uptake and utility, high-quality educational strategies that clearly articulate the supporting regulatory framework should be employed with inpatients, families and providers [33]. This may help reduce uncertainty about the purpose of ACP, as well as what constitutes binding written documentation and the rights and responsibilities of substitute-decision-makers [34]. As a person's preference may change with health or personal circumstances, providing opportunities to prepare or modify existing documentation at regular intervals can help address concerns about not being able to amend documents; or the reluctance of providers to implement documents made some time ago or where instructions are vague [35].

Not all respondents wanted to engage in ACP. Many believed families and healthcare providers already knew what they wanted with respect to end-of-life care and would make the appropriate decision when the time came [36]. This is despite these same respondents reporting that they had not discussed their end-of-life wishes with these individuals. Relying on substitute-decision-maker or provider views does not always guarantee that patients' true preferences will be achieved, especially when conversations have not occurred [8, 18]. Consistent with previous studies [36, 37], patients also voiced concerns about the potential burden on loved ones and perceived irrelevance of ACP to their circumstances.

\section{Implications and future research}

ACP activities are associated with better quality of life and improved compliance with end of life wishes for patients, fewer depressive symptoms and less stress in family members; $[4,5,38]$ and lower costs and fewer hospital presentations [6]. Despite these potential benefits and their estimated limited life expectancy, few inpatients have engaged in all four identified ACP activities.
To increase the probability that a person's actual endof-life wishes are known and followed, the following steps are required. Firstly, there is a need to improve end-of-life communication between patients, their families, and hospital-based providers. Information conveyed during end of life conversations with GPs is rarely available at the time end-of-life decisions are being made in hospital. Secondly, end-of-life conversations should involve the patient, substitute-decisionmaker; and the most senior clinician responsible for leading and coordinating the patient's care, given heightened emotions surrounding topics being discussed [39]. Furthermore, end-of-life wishes and details of designated substitute-decision-makers should be documented in written plans, with mechanisms in place to ensure that these are readily available to all teams involved in the patient's care [39].

\section{Strengths and limitations}

This study provides some of the first patient-reported data about the preferences and experiences of a large group of Australian inpatients with respect to four informal and formal ACP activities. However, there are a number of limitations. While the eligibility criteria reflect a group for whom ACP is particularly relevant, it is a single institution sample which may not be representative of results from other organisations. Replicating the survey across organisations would provide important information of use to clinicians to guide ACP and should be explored [13]. Our sample was primarily Australian born and community-dwelling. Recent Australian data also reported differences in rates of advance care directive ownership across general practice, hospital and residential aged care settings [13]. Surveying patients within each of these settings would help clarify reasons why this disparity may be occurring, including whether it reflects patient preference or represents a gap in care. The cross-sectional nature of the data is also a limitation. Prospective studies that examine people's preferences and experiences over time and the potential impact of their choices on patient and family outcomes are needed.

\section{Conclusions}

Few inpatients in this study had engaged in all four advance care planning (ACP) activities. Fewer inpatients had talked about their wishes for end-of-life care with doctors or recorded their wishes in an advance directive, when compared to having talked about their wishes with their family and appointing a medical substitute decision-makers. Despite an expressed desire to engage in these activities, significant barriers to ACP activities remain. To increase the probability that people's endof-life wishes are known and followed, education of the 
general community about the purpose and potential benefits of ACP is needed. Education and training of community and hospital-based providers is also required to ensure they are able to take a more active role in discussing and enacting end-of-life decisions with patients and their families.

\section{Additional files}

Additional file 1: Standardised Interview Survey items. This lists the interview survey items completed by participants. (DOCX 18 kb)

\section{Abbreviations}

ACD: advance care directive; ACP: advance care planning; GP: general practitioner: USA: United States of America

\section{Acknowledgements}

The authors would like to acknowledge research support from Justin Walsh, Sandra Dowley, Sue Quilty, Sally Millington, Mark and Karina Sanson-Fisher. Thank you to hospital staff and patients for their contribution to this research.

\section{Authors' contributions}

AW and RSF conceived of and designed the study procedures and materials. KN assisted with recruitment. AW undertook data collection with assistance from trained research assistants. TE undertook data analysis. All authors contributed to the drafting of the manuscript and have read and approved the final manuscript

\section{Funding}

This research was supported by an Australian Research Council DECRA (D150101262; AW) and a Strategic Research Partnership Grant (CSR 11-02; RSF) from The Cancer Council NSW. These funding sources had no role in the design of this study and did not have any role during its execution, analyses, interpretation of the data or decision to submit results. This research was also supported by infrastructure funding from University of Newcastle and Hunter Medical Research Institute.

\section{Availability of data and materials}

Datasets are available from the corresponding author on reasonable request.

\section{Ethics approval and consent to participate}

Written informed consent was obtained from all participants prior to completing the interview. The University of Newcastle Human Research Ethics Committee (H-2014-0411) and the Hunter New England Local Health District Human Research Ethics Committee (14/11/19/4.04) approved the study.

\section{Consent for publication}

Not applicable.

\section{Competing interests}

The authors declare that they have no competing interests.

\section{Author details}

${ }^{1}$ Health Behaviour Research Collaborative, School of Medicine and Public Health, Faculty of Health and Medicine, University of Newcastle, Callaghan, NSW 2308, Australia. ${ }^{2}$ Hunter Medical Research Institute, New Lambton Heights, NSW 2305, Australia. ${ }^{3}$ John Hunter Hospital, Hunter New England Local Health District, New Lambton Heights, NSW 2305, Australia. ${ }^{4}$ School of Medicine and Public Health (Medical Education and Professional Development), University of Newcastle, Callaghan, NSW 2308, Australia. ${ }^{5}$ Clinical Research Design and Statistics Support Unit, Hunter Medical Research Institute, New Lambton Heights, NSW 2305, Australia.
Received: 16 November 2018 Accepted: 11 July 2019

Published online: 05 August 2019

\section{References}

1. Sudore RL, Lum HD, You JJ, Hanson LC, Meier DE, Pantilat SZ, Matlock DD, Rietjens JAC, Korfage IJ, Ritchie CS, et al. Defining Advance Care Planning for Adults: A Consensus Definition from a Multidisciplinary Delphi Panel. J Pain Symptom Manag. 2017;53(5):821-32 e821.

2. Rietjens JAC, Sudore RL, Connolly M, van Delden JJ, Drickamer MA, Droger M, van der Heide A, Heyland DK, Houttekier D, Janssen DJA, et al. Definition and recommendations for advance care planning: an international consensus supported by the European Association for Palliative Care. Lancet Oncol. 2017;18(9):e543-51.

3. Sudore RL, Heyland DK, Lum HD, Rietjens JAC, Korfage IJ, Ritchie CS, Hanson LC, Meier DE, Pantilat SZ, Lorenz K, et al. Outcomes that define successful advance care planning: a Delphi panel consensus. J Pain Symptom Manag. 2018;55(2):245-55.e8.

4. Brinkman-Stoppelenburg A, Rietjens JA, Heide A. The effects of advance care planning on end-of-life care: a systematic review. Palliat Med. 2014; 28(8):1000-25.

5. Houben $\mathrm{CH}$, Spruit MA, Groenen MT, Wouters EF, Janssen DJ. Efficacy of advance care planning: a systematic review and meta-analysis. J Am Med Dir Assoc. 2014;15(7):477-89.

6. Molloy DW, Guyatt GH, Russo R, Goeree R, O'Brien BJ, Bedard M. Systematic implementation of an advance directive program in nursing homes: a randomized controlled trial. JAMA. 2000:283(11):1437-44.

7. Sharp T, Moran E, Kuhn I, Barclay S. Do the elderly have a voice? Advance care planning discussions with frail and older individuals: a systematic literature review and narrative synthesis. $\mathrm{Br} J$ Gen Pract. 2013;63(615):e657-68.

8. Bernacki RE, Block SD. Communication about serious illness care goals: a review and synthesis of best practices. JAMA Intern Med. 2014;174(12): 1994-2003.

9. Silveira MJ, Kim SY, Langa KM. Advance directives and outcomes of surrogate decision making before death. N Engl J Med. 2010;362(13):1211-8.

10. Osborn R, Moulds D, Squires D, Doty MM, Anderson C. International survey of older adults finds shortcomings in access, coordination, and patientcentered care. Health Aff (Millwood). 2014;33(12):2247-55

11. Ruseckaite R, Detering KM, Evans SM, Perera V, Walker L, Sinclair C, Clayton $J M$, Nolte L. Protocol for a national prevalence study of advance care planning documentation and self-reported uptake in Australia. BMJ Open. 2017;7(11):e018024.

12. White B, Tilse C, Wilson J, Rosenman L, Strub T, Feeney R, Silvester W. Prevalence and predictors of advance directives in Australia. Intern Med J. 2014;44(10):975-80.

13. Detering KM, Buck K, Ruseckaite R, et al Prevalence and correlates of advance care directives among older Australians accessing health and residential aged care services: multicentre audit study. BMJ Open 2019;9: e025255. https://doi.org/10.1136/bmjopen-2018-025255

14. Orford NR, Milnes SL, Lambert N, Berkeley L, Lane SE, Simpson N, Elderkin T, Bone A, Martin P, Corke C, et al. Prevalence, goals of care and long-term outcomes of patients with life-limiting illness referred to a tertiary ICU. Crit Care Resusc. 2016;18(3):181-8.

15. Hardy JR, Haberecht J, Maresco-Pennisi D, Yates P. Audit of the care of the dying in a network of hospitals and institutions in Queensland. Intern Med J. 2007:37(5):315-9.

16. Michael N, O'Callaghan C, Sayers E. Managing 'shades of grey': a focus group study exploring community-dwellers' views on advance care planning in older people. BMC palliative care. 2017;16(1):2.

17. Michael N, O'Callaghan C, Baird A, Hiscock N, Clayton J. Cancer caregivers advocate a patient-and family-centered approach to advance care planning J Pain Symptom Manag. 2014;47(6):1064-77.

18. Heyland DK, Barwich D, Pichora D, Dodek P, Lamontagne F, You JJ, Tayler C, Porterfield P, Sinuff T, Simon J. Failure to engage hospitalized elderly patients and their families in advance care planning. JAMA Intern Med. 2013;173(9):778-87.

19. Johnson SB, Butow PN, Kerridge I, Bell ML, Tattersall MHN. How well do current measures assess the impact of advance care planning on concordance between patient preferences for end-of-life care and the care received: $a$ methodological review. J Pain Symptom Manag. 2018;55(2):480-95. 
20. Higginson IJ, Sarmento VP, Calanzani N, Benalia H, Gomes B. Dying at home--is it better: a narrative appraisal of the state of the science. Palliat Med. 2013;27(10):918-24.

21. Kupeli N, Candy B, Tamura-Rose G, Schofield G, Webber N, Hicks SE, Floyd T, Vivat B, Sampson EL, Stone P, et al. Tools measuring quality of death, dying, and care, completed after death: systematic review of psychometric properties. Patient. 2019;12(2):183-97.

22. Yadav KN, Gabler NB, Cooney E, Kent S, Kim J, Herbst N, Mante A, Halpern SD, Courtright KR. Approximately one in three US adults completes any type of advance directive for end-of-life care. Health Aff (Millwood). 2017; 36(7):1244-51

23. Torke AM, Siegler M, Abalos A, Moloney RM, Alexander GC. Physicians' experience with surrogate decision making for hospitalized adults. J Gen Intern Med. 2009;24(9):1023-8.

24. Mendoza J, Burns C. Challenges in determining the substitute decision maker: findings from an Australian intensive care unit. Adv Practice Nursing. 2016;1:115.

25. Lovell A, Yates P. Advance care planning in palliative care: a systematic literature review of the contextual factors influencing its uptake 2008-2012. Palliat Med. 2014;28(8):1026-35.

26. Lingler JH, Hirschman KB, Garand L, Dew MA, Becker JT, Schulz R, DeKosky ST. Frequency and correlates of advance planning among cognitively impaired older adults. Am J Geriatr Psychiatry. 2008;16(8):643-9.

27. Bradley SL, Woodman RJ, Tieman JJ, Phillips PA. Use of advance directives by south Australians: results from the health omnibus survey spring 2012. Med J Aust. 2014:201(8):467-9.

28. White B, Tilse C, Wilson J, Rosenman L, Strub T, Feeney R, Silvester W. Prevalence and predictors of advance directives in a ustralia. Intern Med J. 2014;44(10):975-80.

29. You JJ, Downar J, Fowler RA, Lamontagne F, Ma IW, Jayaraman D, Kryworuchko J, Strachan PH, Ilan R, Nijjar AP, et al. Barriers to goals of care discussions with seriously ill hospitalized patients and their families: a multicenter survey of clinicians. JAMA Intern Med. 2015;175(4):549-56.

30. Bester J, Cole CM, Kodish E. The limits of informed consent for an overwhelmed patient: Clinicians' role in protecting patients and preventing overwhelm. AMA J Ethics. 2016;18(9):869-86.

31. Australian Bureau of Statistics: 4839.0 - Patient Experiences in Australia: Summary of Findings, 2014-15. In., vol. 2015; 2015.

32. Malpas PJ. Advance directives and older people: ethical challenges in the promotion of advance directives in New Zealand. J Med Ethics. 2011;37(5):285-9.

33. White B, Willmott L, Tilse C, Wilson J, Lawson D, Pearce A, Dunn J, Aitken JF, Feeney R, Jowett $\mathrm{S}$. Community knowledge of law at the end of life: availability and accessibility of web-based resources. Aust Health Rev. 2017; 42(3):266-71.

34. Cartwright C, Montgomery J, Rhee J, Zwar N, Banbury A. Medical practitioners' knowledge and self-reported practices of substitute decision making and implementation of advance care plans. Intern Med J. 2014; 44(3):234-9.

35. Martin RS, Hayes B, Gregorevic K, Lim WK. The effects of advance care planning interventions on nursing home residents: a systematic review. J Am Med Dir Assoc. 2016;17(4):284-93.

36. Scott I. Difficult but necessary conversations - the case for advance care planning. Med J Aust. 2013;199(10):662-6.

37. Johnson S, Butow P, Kerridge I, Tattersall M. Advance care planning for cancer patients: a systematic review of perceptions and experiences of patients, families, and healthcare providers. Psychooncology. 2016;25(4):362-86.

38. Detering KM, Hancock AD, Reade MC, et al. The impact of advance care planning on end of life care in elderly patients: randomised controlled trial. BMJ Open. 2010;340:1345.

39. Australian Commission on Safety and Quality in Health Care: National Consensus Statement: essential elements for safe and high-quality end-oflife care. In. Sydney; 2015.

\section{Publisher's Note}

Springer Nature remains neutral with regard to jurisdictional claims in published maps and institutional affiliations.

Ready to submit your research? Choose BMC and benefit from:

- fast, convenient online submission

- thorough peer review by experienced researchers in your field

- rapid publication on acceptance

- support for research data, including large and complex data types

- gold Open Access which fosters wider collaboration and increased citations

- maximum visibility for your research: over $100 \mathrm{M}$ website views per year

At BMC, research is always in progress.

Learn more biomedcentral.com/submissions 